\title{
Utilisation of thermal annealing to record multiplexed FBG sensors in multimode microstructured polymer optical fibre.
}

\author{
Ian P. Johnson, David J. Webb, Kyriacos Kalli . \\ Photonics Research Group, Aston University, Birmingham, B4 7ET, UK \\ *Nanophotonics Research Laboratory, Cyprus University of Technology, Cyprus
}

\begin{abstract}
Fibre Bragg gratings have been UV inscribed in multimode microstructured polymer optical fibre in both the $1550 \mathrm{~nm}$ and $800 \mathrm{~nm}$ spectral regions. Thermally annealing the fibre at $71^{\circ} \mathrm{C}$ has been shown to shrink the fibre length and as a result a permanent negative Bragg wavelength shift is observed. The blue shift can be tuned between 0-16nm in the $1550 \mathrm{~nm}$ spectral region and $0-6 \mathrm{~nm}$ in the $800 \mathrm{~nm}$ spectral region, depending on the duration the heat is applied before a saturation level is reached and the fibre stops shrinking in the region of 2 hours. Exploiting this, wavelength division multiplexed sensors have been UV inscribed in both the $1550 \mathrm{~nm}$ and $800 \mathrm{~nm}$ regions using a single phase mask for each wavelength region. The $800 \mathrm{~nm}$ sensor takes advantage of the lower attenuation of poly (methyl methacrylate) of $2 \mathrm{~dB} / \mathrm{m}$ compared to $100 \mathrm{~dB} / \mathrm{m}$ at $1550 \mathrm{~nm}$.
\end{abstract}

Keywords: polymer optical fibre, fibre Bragg grating, microstructured polymer optical fibre, photonic crystal fibre, wavelength division multiplexing, thermal annealing.

\section{INTRODUCTION}

Within the last decade or so fibre Bragg gratings (FBGs) have been UV inscribed in step index polymer optical fibre (POF)[1] and microstructured POF (mPOF)[2], both of which are based on poly (methyl methacrylate) (PMMA) as the fundamental material. Furthermore in recent years applications of polymer FBGs out of the laboratory have been documented[3] and additionally gratings have been inscribed in multi-mode mPOF (MMmPOF) at 827nm[4]. The fabrication of gratings at $827 \mathrm{~nm}$ allows more practical applications outside of the laboratory as the fibre attenuation is relatively small $(2 \mathrm{~dB} / \mathrm{m})[5]$ compared to the attenuation at higher wavelengths, normally around $100 \mathrm{~dB} / \mathrm{m}$ at $1550 \mathrm{~nm}$ and $10 \mathrm{~dB} / \mathrm{m}$ at $980 \mathrm{~nm}$ in PMMA fibre[5]; furthermore broadband semiconductor light sources and cheap detectors are readily available in the $800 \mathrm{~nm}$ region. Fabrication of FBGs in MMmPOF also lends itself to applications providing ease of handling, ease of connection to light sources and interrogation equipment and gives the opportunity for cheaper light sources, when comparing the costs of broad area emitters to a single transverse mode light source. In comparison to silica optical fibre, POF has a Young's modulus 25 times smaller than that of silica fibre[6], lending itself to applications where silica may otherwise stiffen a material and reduce the strain monitored by the sensor[3]. Furthermore POF has a high recoverable strain limit resulting in a tuning range of a FBG of up to $13 \%[7]$. In addition POF is suitable for in-vivo sensing applications due to its non-brittle, flexible and clinically acceptable material properties[8].

In this paper we report on our success in fabricating wavelength division multiplexed (WDM) sensors utilising the thermal annealing properties of POF allowing the use of a single phase mask for each sensor fabrication. This technique was employed to produce sensors in both the $1550 \mathrm{~nm}$ and $800 \mathrm{~nm}$ spectral regions.

\section{FBG UV INSCRIPTION AND SPECTRUM INTERROGATION}

The POF used in this work was MMmPOF, made purely from PMMA and obtained from Kyriama Pty. The MMmPOF was manufactured as described by Barton et al[9] without the sleeving phase. The fibre had an outer diameter of $150 \mu \mathrm{m}$; within the fibre were three rings of holes encompassing a $50 \mu \mathrm{m}$ solid core. As was demonstrated by Dobb et al[2] a

21st International Conference on Optical Fiber Sensors, edited by Wojtek J. Bock, Jacques Albert, Xiaoyi Bao, Proc. of SPIE Vol. 7753, 77536T · (C) 2011 SPIE · CCC code: 0277-786X/11/\$18 · doi: 10.1117/12.885926 
continuous wave helium cadmium (HeCd) laser with an output wavelength of $325 \mathrm{~nm}$ and power of $30 \mathrm{~mW}$ was used to fabricate FBGs in the MMmPOF. A relatively simple UV inscription setup was used for the fabrications, however the emphasis of the setup is to ensure the fibre is immobile along the inscription length as fabrication times using this fibre can be around one hour. The MMmPOF was taped along a horizontal v-groove to ensure alignment of the UV laser beam to the fibre core throughout the inscription. The laser beam of width $1.8 \mathrm{~mm}$ was focussed vertically downwards using a $10 \mathrm{~cm}$ cylindrical lens to expose the MMmPOF through a phase mask, which is placed above the POF. In this paper we present results from gratings in both the C-Band wavelength region and the lower $800 \mathrm{~nm}$ region and consequently two different phase masks are individually used. The first mask had a uniform period of $1057.2 \mathrm{~nm}$ resulting in a Bragg wavelength around $1562 \mathrm{~nm}[10]$ and the second mask had a period of $557.2 \mathrm{~nm}$ resulting in a Bragg wavelength of $828 \mathrm{~nm}$.

The Bragg grating reflection spectra were interrogated using two multimode 50:50 silica couplers, one manufactured to operate in the $1550 \mathrm{~nm}$ region and the second in the $800 \mathrm{~nm}$ region. Firstly light was launched into a $20 \mathrm{~m}$ spool of $50 / 125 \mu \mathrm{m}$ silica fibre, to approach an equilibrium modal distribution within the multi-mode fibre. The light source used depended on the Bragg grating to be interrogated. Light was launched into the core of the MMmPOF by butt coupling an FC/APC connector on one arm of the coupler to the MMmPOF and optimised by controlling the coupling using a $\mathrm{x}, \mathrm{y}, \mathrm{z}$ translation stage, with index matching gel applied between the two fibres so as to reduce Fresnel reflections. The end face of the MMmPOF was prepared with a $80^{\circ} \mathrm{C}$ razor blade cleave[11]. The Bragg reflection was captured on an optical spectrum analyser (OSA) with multimode fibre input capability (HP 7000 series). Figure 1a shows a FBG fabricated in MMmPOF with a Bragg wavelength of $1561.75 \mathrm{~nm}$ with a FWHM of $2.82 \mathrm{~nm}$. Figure $1 \mathrm{~b}$ shows a FBG fabricated in the same fibre with a Bragg wavelength of $828.36 \mathrm{~nm}$ with a FWHM of $0.5 \mathrm{~nm}$. Both gratings were UV exposed for one hour.
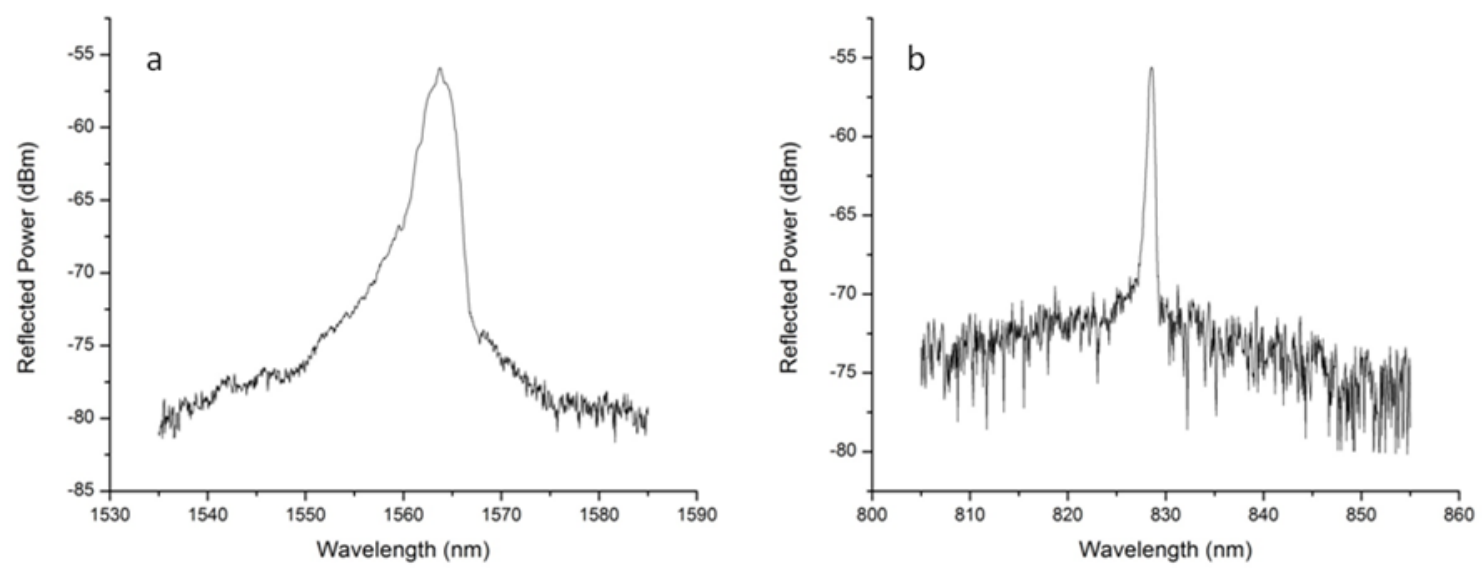

Figure 1: a) Reflection spectrum of FBG fabricated in MMmPOF at $1562 \mathrm{~nm}$, Bandwidth resolution $0.5 \mathrm{~nm}$. b) Reflection spectrum of FBG fabricated in MMmPOF at $828 \mathrm{~nm}$, Bandwidth resolution $0.5 \mathrm{~nm}$.

\section{THERMAL ANNEALING}

By utilising the thermal characteristics of POF Carroll et al[10] demonstrated that a permanent blue shift can be induced of up to $18.5 \mathrm{~nm}$ in the Bragg wavelength of a FBG initially at $1562 \mathrm{~nm}$ as a result of heating the fibre to $92^{\circ} \mathrm{C}$. This phenomenon occurs as a result of axial orientation of the polymer chains when the fibre is pulled under tension during manufacturing. As the fibre is heated a point will be met where the orientation of the chains relaxes, causing the fibre to shrink in length and increase in diameter. Previous reports claim the shrinkage is a function of the drawing tension and discuss that the temperature at which the fibre starts to shrink is a function of the thermal history of the fibre determined by the fibre drawing parameters[12]. 
Figure 2 demonstrates the blue shift of the Bragg wavelength observed when repetitively performing the thermal annealing of the MMmPOF in which a FBG was inscribed for different time periods. Three different samples of MMmPOF were used, each inscribed with a Bragg grating at $1562 \mathrm{~nm}$ similar to Figure 1a. Each of the three gratings was repeatedly placed in the oven pre-heated to $71^{\circ} \mathrm{C}$ for various lengths of time with the Bragg wavelength measured between each cycle. Grating 1 was cycled in 10 minute steps, grating 2 was cycled in 20 minute steps and grating 3 was cycled in 30 minute steps. The Bragg wavelength measured between each step for all three fibres is shown in Figure 2. It may be seen that all three data sets are in broad agreement and define a thermal annealing curve, which allows the Bragg wavelength of gratings inscribed in MMmPOF to be tuned between a $0 \mathrm{~nm}$ and $-16 \mathrm{~nm}$ range, provided the POF has not been pre-annealed. Figure 3 demonstrates the change in Bragg wavelength can be controlled by regulating the amount of time the fibre is placed in the pre-heated oven. A saturation level of the Bragg wavelength shift would appear around two hours of thermal annealing at $71^{\circ} \mathrm{C}$ where the fibre stops shrinking significantly.

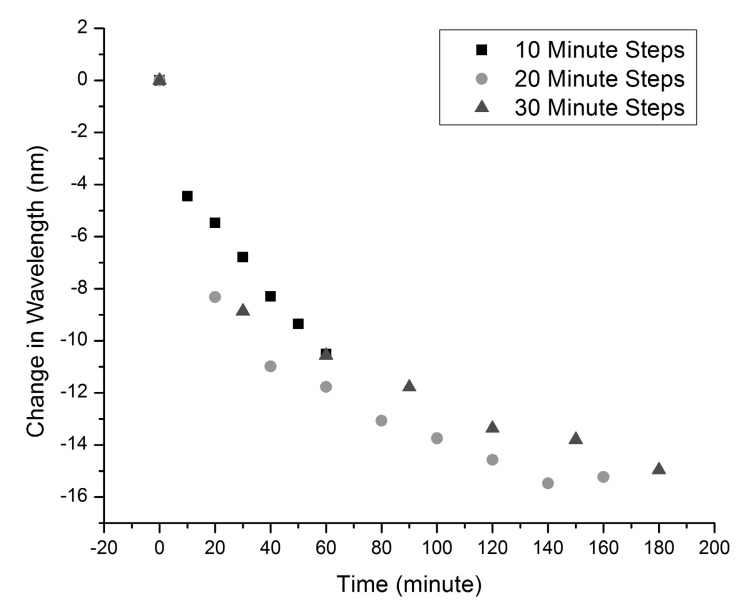

Figure 2 Blue shift of Bragg wavelength observed when thermally annealing the MMmPOF

\section{WAVELENGTH DIVISION MULIPLEXED FBG SENSOR}

Previously, WDM sensors have been manufactured exploiting the POF thermal annealing properties[13] but using two different phase masks. However expanding on this and exploiting the results established in Figure 2 it is possible to fabricate a WDM sensor of three FBGs in both the C-Band and 800nm wavelength region each using a single phase mask, as shown in Figure $3 a$ \& b.

Figure 3a presents a WDM sensor which was fabricated by first inscribing a grating at $1562 \mathrm{~nm}$. The Bragg wavelength was then shifted by $8.2 \mathrm{~nm}$ via thermally annealing the fibre at $71^{\circ} \mathrm{C}$ for 30 minutes. A second grating was then inscribed at $1562 \mathrm{~nm}$ and the fibre was annealed for six hours to ensure a saturation level of shrinkage was achieved. Finally a third FBG was inscribed at $1562 \mathrm{~nm}$. Figure $3 \mathrm{~b}$ presents a WDM sensor which was fabricated by pre-annealing fibre at $71^{\circ} \mathrm{C}$ for ten minutes so to avoid the initial large wavelength shift. A FBG was then inscribed into the pre-annealed fibre, producing a grating response at $828 \mathrm{~nm}$. The fibre was then thermally annealed at $71^{\circ} \mathrm{C}$ for 30 minutes initiating a permanent blue shift of $3.5 \mathrm{~nm}$. A second FBG was then inscribed at $828 \mathrm{~nm}$ and the fibre was again annealed at $71^{\circ} \mathrm{C}$ for two hours, causing the first grating to shift $1 \mathrm{~nm}$ and the second grating to shift $3.2 \mathrm{~nm}$. Finally a third FBG was inscribed at $828 \mathrm{~nm}$. The gratings were separated by $10 \mathrm{~mm}$.

In Figure 3a the spectral response of gratings 1 and 2 overlap after annealing. The annealing time of 6 hours after grating 2 was inscribed was too long, which allowed grating 2 to shift too much compared to the wavelength shift of grating 1 . In Figure 3b, the Bragg response of gratings 1 and 2 are weaker than grating 3; this may possibly be due to the thermal annealing and the close proximity of the UV inscription beam to the previously inscribed gratings weakening their Bragg response. 

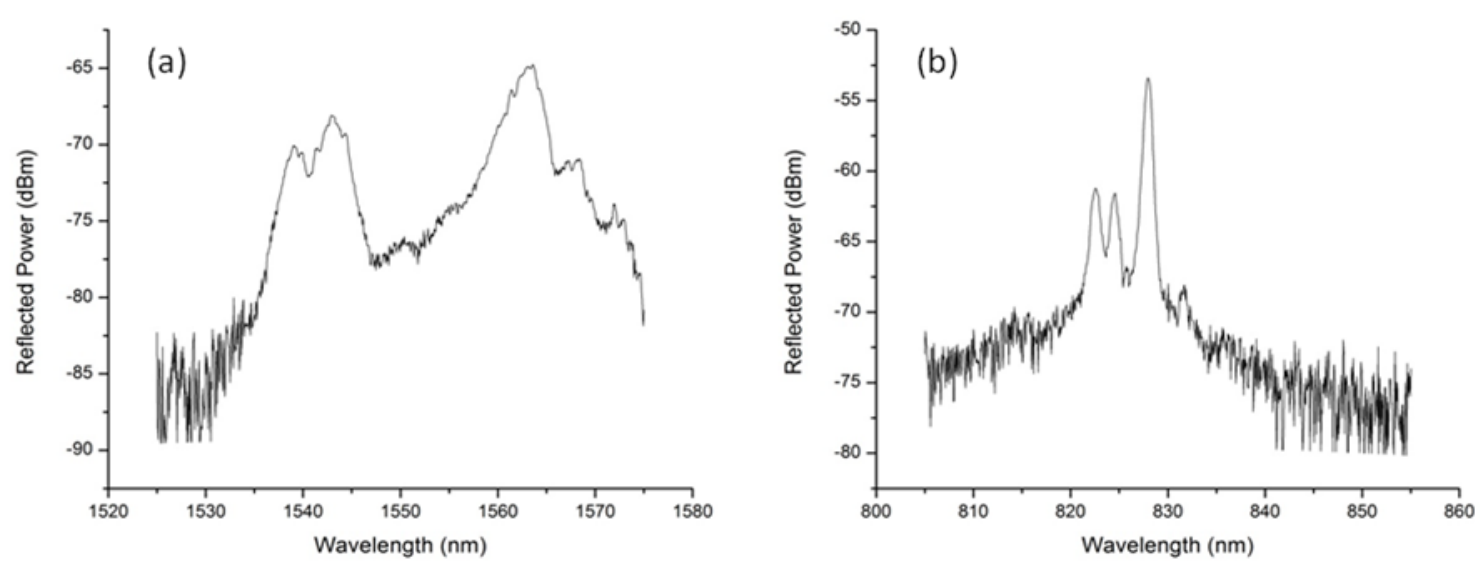

Figure 3a: WDM sensor within the $1550 \mathrm{~nm}$ region. b: WDM sensor within the $800 \mathrm{~nm}$ region

\section{CONCLUSIONS}

In summary, it has been established that both $1562 \mathrm{~nm}$ and $828 \mathrm{~nm}$ gratings can be UV inscribed in MMmPOF. The thermal annealing characteristics of POF and the ability to shrink the fibre provides the possibility to thermally tune the Bragg wavelength with a blue wavelength shift between $0 \mathrm{~nm}$ and $16 \mathrm{~nm}$ in the $1550 \mathrm{~nm}$ spectral region and between $0 \mathrm{~nm}$ and $6 \mathrm{~nm}$ in the $800 \mathrm{~nm}$ spectral region, until a saturation point is reached and the fibre will not shrink further. As the results have shown the amount of blue shift is dependent on the duration of annealing and because of this a number of FBGs can be inscribed within the same fibre using a single mask when the fibre is annealed appropriately between inscriptions. It is believed this is the first work to demonstrate WDM using a single phase mask and in particular the ability to manufacture such sensors within the $800 \mathrm{~nm}$ region gives more potential for applications.

\section{ACKNOWLEDGEMENTS}

The authors would like to acknowledge the European Union framework 7 project PHOtonic Skins For Optical Sensing (PHOSFOS) and I Johnson would like to acknowledge the UK Engineering and Physical Sciences Research Council (EPSRC).

\section{REFERENCES}

[1] Z. Xiong, G. D. Peng, B. Wu et al. Ieee Photonics Technology Letters, 11(3), 352-354 (1999).

[2] H. Dobb, D. J. Webb, K. Kalli et al., Optics Letters, 30(24), 3296-3298 (2005).

[3] C. C. Ye, J. M. Dulleu-Barton, D. J. Webb et al., Proc of SPIE 2009, 7503, Paper 75030M

[4] I. P. Johnson, K. Kalli, and D. J. Webb, Electronics Letters, 46(17), 1217-U74 (2010).

[5] H.P.A.v.d. Boom, W. Li, P. K.v. Bennekom et al., Ieee Journal of Selected Topics in Quantum Elec, 7(3), 461-470 (2001).

[6] M. Silva-Lopez, A. Fender, W. N. MacPherson et al., Optics Letters, 30(23), 3129-3131 (2005).

[7] H. B. Liu, H. Y. Liu, G. D. Peng et al., Optics Communications, 219(1-6), 139-142 (2003).

[8] F. Baldini, and A. G. Mignani, MRS Bulletin, 27(5), 383-387 (2002).

[9] G. Barton, M. A. van Eijkelenborg, G. Henry et al., Optical Fiber Technology, 10(4), 325-335 (2004).

[10] K. E. Carroll, C. Zhang, D. J. Webb et al., Optics Express, 15(14), 8844-8850 (2007).

[11] S. H. Law, J. D. Harvey, R. J. Kruhlak et al., Optics Communications, 258(2), 193-202 (2006).

[12] T. Ishigure, M. Hirai, M. Sato et al., Journal of Applied Polymer Science, 91(1), 404-409 (2004).

[13] I. P. Johnson, D. J. Webb, K. Kalli et al., SPIE Proceedings Vol: 7714, Paper 77140D. 